\title{
Microwave Synthesized ZnO Nanorod Arrays for UV Sensors: A Seed Layer Annealing Temperature Study
}

\author{
Ana Pimentel *, Sofia Henriques Ferreira, Daniela Nunes, Tomas Calmeiro, Rodrigo Martins \\ and Elvira Fortunato * \\ i3N/CENIMAT, Department of Materials Science, Faculty of Science and Technology, Universidade NOVA de \\ Lisboa, Campus de Caparica, Caparica 2829-516, Portugal; sofialhf@gmail.com (S.H.F.); \\ danielasilvanunes@gmail.com (D.N.); tomasrcalmeiro@gmail.com (T.C.); rm@uninova.pt (R.M.) \\ * Correspondence: acgp@campus.fct.unl.pt (A.P.); emf@fct.unl.pt (E.F.); Tel.: +351-21-2948562 (A.P. \& E.F.); \\ Fax: +351-21-2948558 (A.P. \& E.F.)
}

Academic Editor: Dinesh Agrawal

Received: 27 February 2016; Accepted: 15 April 2016; Published: 20 April 2016

\begin{abstract}
The present work reports the influence of zinc oxide $(\mathrm{ZnO})$ seed layer annealing temperature on structural, optical and electrical properties of $\mathrm{ZnO}$ nanorod arrays, synthesized by hydrothermal method assisted by microwave radiation, to be used as UV sensors. The ZnO seed layer was produced using the spin-coating method and several annealing temperatures, ranging from 100 to $500{ }^{\circ} \mathrm{C}$, have been tested. X-ray diffraction (XRD), scanning electron microscopy (SEM), atomic force microscopy (AFM) and spectrophotometry measurements have been used to investigate the structure, morphology, and optical properties variations of the produced $\mathrm{ZnO}$ nanorod arrays regarding the seed layer annealing temperatures employed. After the growth of $\mathrm{ZnO}$ nanorod arrays, the whole structure was tested as UV sensors, showing an increase in the sensitivity with the increase of seed layer annealing temperature. The UV sensor response of $\mathrm{ZnO}$ nanorod arrays produced with the seed layer annealed temperature of $500{ }^{\circ} \mathrm{C}$ was 50 times superior to the ones produced with a seed layer annealed at $100^{\circ} \mathrm{C}$.
\end{abstract}

Keywords: ZnO nanostructures; spin-coating; hydrothermal synthesis; microwave; UV sensors

\section{Introduction}

Zinc oxide $(\mathrm{ZnO})$ is an n-type semiconductor that has been extensively studied due to its unique properties, namely its direct and wide band gap (3.37 eV) and high exciton binding energy $(60 \mathrm{meV})$ at room temperature [1]. These exceptional properties allow $\mathrm{ZnO}$ to behave as an efficient semiconductor and, therefore, to be applied in several functional devices, such as thin film transistors [2,3], light emitting diodes (LEDs) [4], UV/ozone sensors [5-7], biosensors [8,9], piezoelectric devices [10,11], among others.

$\mathrm{ZnO}$ can be easily synthesized into different morphologies, such as nanorods, nanotubes, nanoflowers, nanotetrapods, nanoribbons or nanoneedles, by adjusting the synthesis conditions and methods [4,12-16]. In particular, $\mathrm{ZnO}$ nanorods (NRs) have attracted much attention mainly due to their high surface-to-volume ratio and high sensitivity under ambient conditions, thus making them highly appealing for sensing applications [17-19].

$\mathrm{ZnO}$ NRs have been mostly synthesized by bottom up techniques, including chemical vapor deposition (CVD) [18], electrodeposition [20], pulsed laser deposition (PLD) [21], spray pyrolysis [22], and hydrothermal/solvothermal synthesis, which includes either conventional heating [23] or microwave radiation [24-26]. Recently, hydrothermal/solvothermal syntheses have been preferred to the other techniques, since they have proven to be low temperature and low cost methods, despite being versatile for producing $\mathrm{ZnO}$ nanoparticles. Moreover, these latter synthesis routes can be allied to 
facile and low cost techniques for the deposition of the seed layer, namely the spin-coating method [27], obtaining them in continuous and uniform arrays.

Microwave assisted synthesis represents an attractive alternative when compared to conventional heating, as it offers the opportunity to complete reactions in minutes. This celerity is possible due to the fact that microwaves transfer energy directly to the reactive species [28]. Moreover, this synthesis route has been used for other materials, forming homogeneous and uniform nanostructured films [29,30].

The present work reports the synthesis of $\mathrm{ZnO}$ nanorod arrays by the hydrothermal method assisted by microwave radiation, where the $\mathrm{ZnO}$ seed layer was deposited by spin-coating and glass was used as substrates. The microwave assisted synthesis conditions were kept constant. However, the effect of the annealing temperatures of the $\mathrm{ZnO}$ seed layer was investigated. The annealing temperatures tested ranged from $100{ }^{\circ} \mathrm{C}$ to $500^{\circ} \mathrm{C}$, and their effect on the seed layer was correlated to the final structural, morphological and optical properties of $\mathrm{ZnO}$ nanorods arrays. After an extensive characterization, the resulting $\mathrm{ZnO}$ nanorod arrays were tested as UV sensors.

\section{Results and Discussion}

\subsection{Thermal Analysis}

In order to understand the influence on the annealing temperature on the final properties of the $\mathrm{ZnO}$ nanorod arrays, differential scanning calorimetric (DSC) measurements of their prior solutions, reactants and solvents, individually, were carried out (zinc acetate, ethanolamine and 2-methoxyethanol). The results are presented on Figure 1.
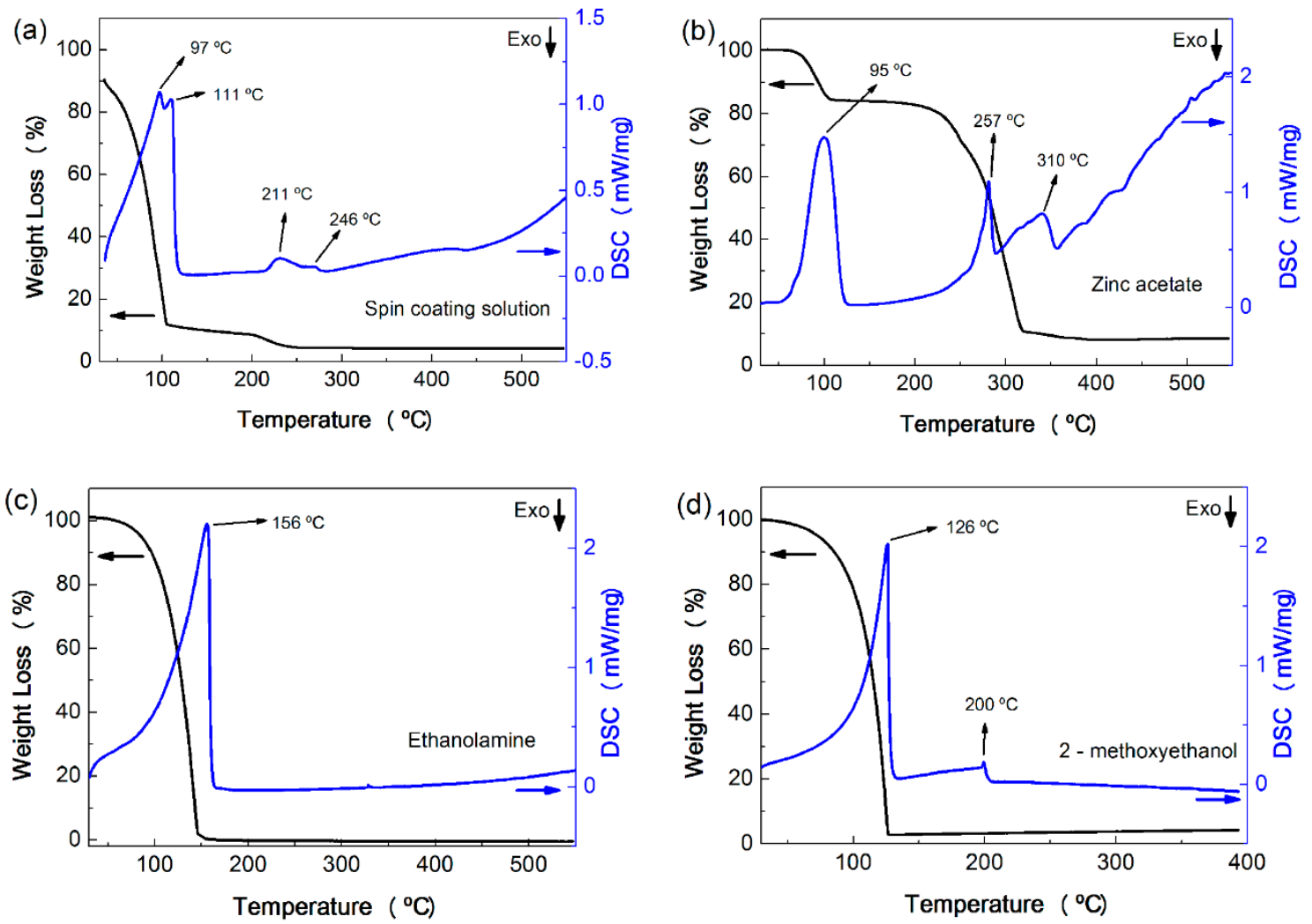

Figure 1. TG/DSC curves of the: (a) solution used in the formation of $\mathrm{ZnO}$ seed layer; (b) zinc acetate; (c) ethanolamine; and (d) 2-methoxyethanol.

Ethanolamine presents a boiling point of $170{ }^{\circ} \mathrm{C}$ and a boiling interval of $69-70{ }^{\circ} \mathrm{C}$ (Figure 1c) and acts as a complexing agent, which retards the $\mathrm{Zn}^{2+}$ condensation; however, its presence also 
increases the $\mathrm{pH}$, which promotes the formation of $\mathrm{ZnO}$ [31]. The use of 2-methoxyethanol, also with a high boiling point, around $125^{\circ} \mathrm{C}$ (Figure 1d), will help the formation of aligned grain growth. Ohyama et al. [32] reported that solvents with low boiling points disturb the aligned grain growth in the film. Solvents with a high boiling point result in strongly preferential orientation of $\mathrm{ZnO}$ crystals, since they evaporate more slowly when heating, allowing the structural relaxation of the film before crystallization [33].

The DSC results of the solution used for the $\mathrm{ZnO}$ seed layer deposition, as well as their reactants and solvents are presented in Figure 1a. The DSC curve displayed a strong endothermic peak composed by two small peaks at $97^{\circ} \mathrm{C}$ and $111^{\circ} \mathrm{C}$, which corresponds to the evaporation of the solvent in the solution (water and 2-methoxyethanol). This peak is accompanied by an expressive weight loss due to material evaporation. Between $200{ }^{\circ} \mathrm{C}$ and $250{ }^{\circ} \mathrm{C}$, there are two small endothermic peaks, accompanied by a small weight loss (about $5 \%$ ). These peaks can be correlated to the decomposition of 2-methoxyethanol, residual organics and the ethanolamine, that can occur between $204^{\circ} \mathrm{C}$ and $232{ }^{\circ} \mathrm{C}$ [32]. Zinc acetate starts to dehydrate becoming anhydrous zinc acetate around $100{ }^{\circ} \mathrm{C}$. Further decomposition of anhydrous zinc acetate from 150 to $280{ }^{\circ} \mathrm{C}$ (see Figure $1 \mathrm{~b}$ ) causes the formation of $\mathrm{Zn}_{4} \mathrm{O}\left(\mathrm{CH}_{3} \mathrm{CO}_{2}\right)_{6}$, which finally decomposes into $\mathrm{ZnO}$ [34]. By the thermal analysis of solution (Figure 1a), it is possible to observe that the final weight loss occurs between $200{ }^{\circ} \mathrm{C}$ and $250{ }^{\circ} \mathrm{C}$ attesting that no further decomposition occurred after this temperature. Since the boiling points of the solvents 2-methoxiethanol and ethanolamine are $125^{\circ} \mathrm{C}$ and $170{ }^{\circ} \mathrm{C}$, respectively, it can be concluded that annealing temperatures above $200^{\circ} \mathrm{C}$ may be required for those to vaporize completely.

\subsection{Structure and Morphology}

In order to structurally characterize the ZnO nanorod arrays, XRD, SEM and AFM experiments were carried out. The $\mathrm{ZnO}$ nanorod synthesis was carried out with a microwave power input of $100 \mathrm{~W}$ and a constant temperature of $100{ }^{\circ} \mathrm{C}$, for $60 \mathrm{~min}$. Figure 2 presents XRD diffractograms of the $\mathrm{ZnO}$ materials (seed layers and nanorod arrays). A single peak can be observed at $2 \theta=34.4^{\circ}$, which is fully assigned to plane (002) of hexagonal wurtzite $\mathrm{ZnO}$ structure and displaying lattice constants of $\mathrm{a}=0.3296 \mathrm{~nm}$ and c $=0.5207 \mathrm{~nm}$ in accordance to Reference [14]. This result is attributed to the low surface energy of the (002) plane, which induced the growth of grains along this plane rather than along other orientation [35]. The results confirm that pure and very well aligned $\mathrm{ZnO}$ nanostructures were obtained.

The peak intensity of the (002) plane is found to increase with increasing annealing temperature, for seed layer and nanorod arrays, indicating that the degree of crystal orientation, as well as grain sizes increased with the increase of annealing temperature. The low intensity of (002) diffraction peak of seed layer annealed at $100{ }^{\circ} \mathrm{C}$ indicates that the thin film is nearly amorphous. This latter result is in consonance with Ohyama [32], which reported that the use of 2-methoxiethanol and ethanolamine, with high boiling points, will produce strongly preferred orientated $\mathrm{ZnO}$ nanocrystals. Higher annealing temperatures ensured higher preferred orientation regarding the (002) plane, which can be associated to the structural relaxation of the gel film before crystallization. However, the growth of $\mathrm{ZnO}$ nanorod arrays on amorphous thin film (annealed at $100^{\circ} \mathrm{C}$ ) resulted in a highly crystalline $\mathrm{ZnO}$ nanorods, meaning that the amorphous $\mathrm{ZnO}$ seed layer does not limit the growth along the (002) plane [27].

The grain sizes of $\mathrm{ZnO}$ thin films and nanorod arrays were calculated from Scherre's equation [36]:

$$
D=0.94 \lambda / \beta \cos \theta
$$

where $\lambda$ is the wavelenght of the X-ray radiation; $\theta$ is the Bragg's angle; and $\beta$ is the full width at half maximum. In Table 1 are descriminated the grain sizes of the $\mathrm{ZnO}$ seed layers and $\mathrm{ZnO}$ nanorod arrays, for the different annealing temperatures. An increase in the annealing temperature generally leads to increase of crystallite size, which can be attributed to the increase of atoms mobility and consequently 
the increase of surface diffusion. These phenomena enable these atoms to migrate longer distances and occupy lattice sites with favorable stable energies. In turn, the crystallite size increase due to a surface energy minimization [37].
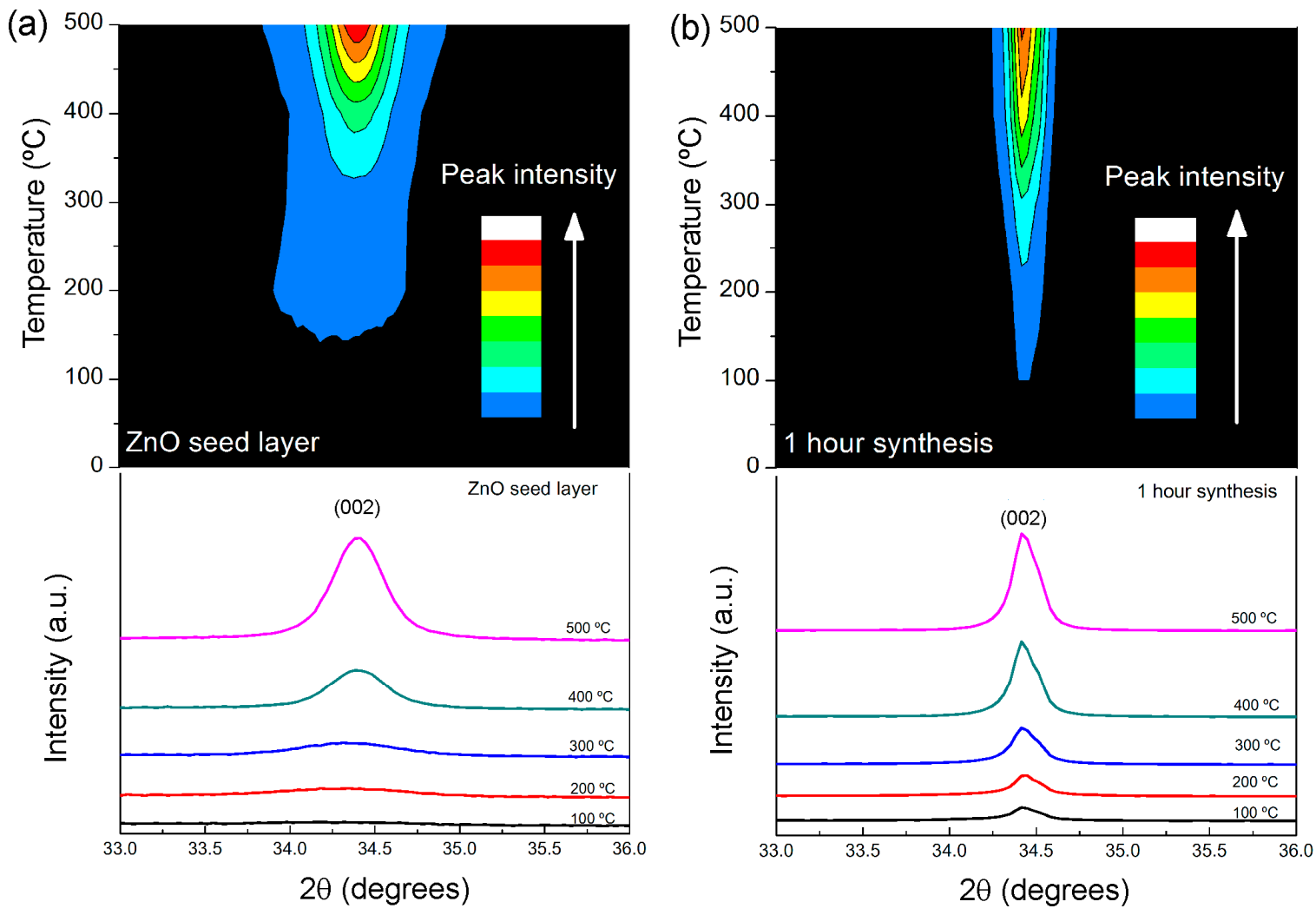

Figure 2. XRD diffractograms of: (a) ZnO thin films deposited by spin-coating; and (b) ZnO nanorod arrays grown by hydrothermal method assited by microwave radiation for $1 \mathrm{~h}$.

Table 1. Crystallite sizes of $\mathrm{ZnO}$ thin films (seed layers) and $\mathrm{ZnO}$ nanorod arrays, obtained with Scherrer's equation.

\begin{tabular}{cccccc}
\hline Annealing Temperature & $\mathbf{1 0 0}{ }^{\circ} \mathbf{C}$ & $\mathbf{2 0 0}{ }^{\circ} \mathbf{C}$ & $\mathbf{3 0 0}{ }^{\circ} \mathbf{C}$ & $\mathbf{4 0 0}^{\circ} \mathbf{C}$ & $\mathbf{5 0 0}^{\circ} \mathbf{C}$ \\
\hline Seed Layer (nm) & 9.426 & 11.055 & 13.388 & 23.449 & 25.725 \\
MW 60 min (nm) & 38.621 & 40.779 & 47.235 & 54.972 & 56.274 \\
\hline
\end{tabular}

SEM and AFM measurements were carried out for the $\mathrm{ZnO}$ seed layers produced with different annealing temperatures and the surface topography images are presented in Figure 3. The $\mathrm{ZnO}$ seed layers showed an increase of roughness with the annealing temperature, where the appearance of nanostructures became discernible, for higher annealing temperatures. From 3D AFM images in Figure $3 \mathrm{f}-\mathrm{j}$, the roughness increase with temperature can be clearly seen. The roughness values were found to be $1.34 \mathrm{~nm}, 1.78 \mathrm{~nm}, 2.51 \mathrm{~nm}, 2.82 \mathrm{~nm}$ and $6.89 \mathrm{~nm}$, for seed layers annealed at $100{ }^{\circ} \mathrm{C}, 200^{\circ} \mathrm{C}$, $300{ }^{\circ} \mathrm{C}, 400{ }^{\circ} \mathrm{C}$ and $500{ }^{\circ} \mathrm{C}$, respectively. The increase of roughness can be associated with the growth of the crystals, thus being consistent with the XRD results. 


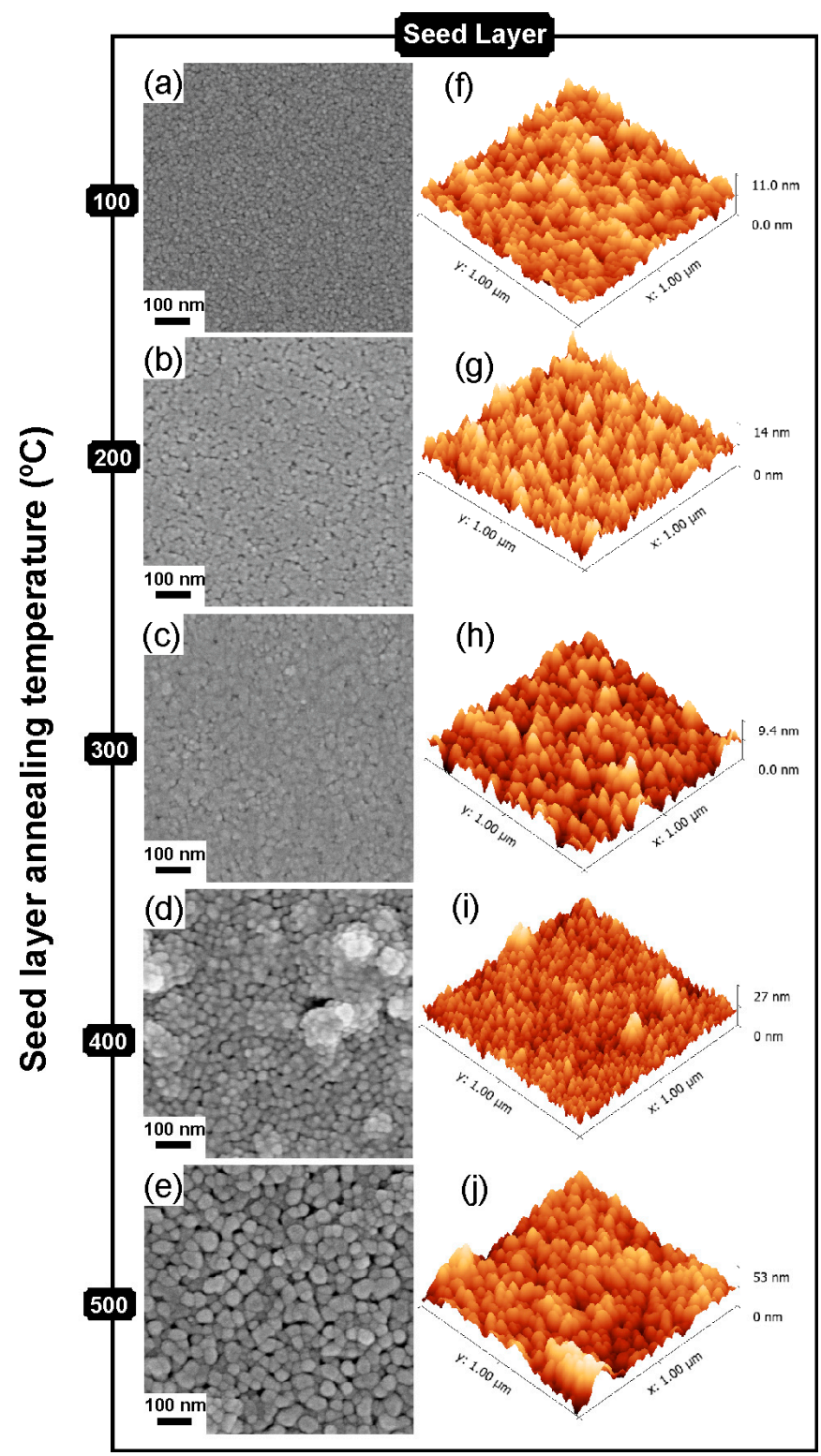

Figure 3. (a-e) SEM images; and (f-j) AFM images of $\mathrm{ZnO}$ seed layers produced with different annealing temperature $\left(100^{\circ} \mathrm{C}, 200^{\circ} \mathrm{C}, 300^{\circ} \mathrm{C}, 400{ }^{\circ} \mathrm{C}\right.$ and $500^{\circ} \mathrm{C}$, respectively).

Regarding the $\mathrm{ZnO}$ nanorod arrays synthesized by hydrothermal method and assisted by microwave radiation, the density and diameter of the nanorods clearly increase with the increase of annealing temperature (see Figure 4). It is also possible to observe that with the increase of annealing temperature, the $\mathrm{ZnO}$ nanorod arrays showed a more homogeneous growth when compared to lower temperatures used. This inhomogeneous growth of $\mathrm{ZnO}$ nanorods for lower annealing temperatures (up to $300^{\circ} \mathrm{C}$ ) can be confirmed with the SEM cross-section images (see Figure $4 \mathrm{f}-\mathrm{j}$ ), where it is possible to observe the presence of abnormal nanorods. It is also possible to observe that the columnar $\mathrm{ZnO}$ nanocrystals are well aligned along the substrate with the $c$-axis oriented perpendicular to the substrate surface. The $\mathrm{ZnO}$ nanorod length increased from about 180 to $350 \mathrm{~nm}$ with the increase of temperature from 100 to $300{ }^{\circ} \mathrm{C}$. For higher temperature, the nanorod length decreased, however they became clearly thicker.

The increase in $\mathrm{ZnO}$ nanorod length is due to the increase of reactivity of the seed layer surface associated to the increase of annealing temperature. The $\mathrm{ZnO}$ crystal structure consist of alternating 
planes composed of coordinated $\mathrm{Zn}$ and $\mathrm{O}$ atoms along the $c$-axis direction. Usually the $\mathrm{Zn}$-terminated polar (0001) plane is at the top surface of the $\mathrm{ZnO}$ crystal structure, whereas the O-terminated polar (0001) plane is at the bottom surface, causing a normal dipole moment and a polar surface of $\mathrm{ZnO}$ seed layer $[24,38]$. The presence of two charges $\left(\mathrm{Zn}^{2+}\right.$ and $\mathrm{OH}^{-}$ions) in the hydrothermal solution results in attraction toward the polar surface of $\mathrm{ZnO}$ seed layer. The reactivity of $\mathrm{ZnO}$ seed layer can be improved with the increase of annealing temperature, which will be stronger than the electrostatic interaction of the polar surface of the $\mathrm{ZnO}$ seed layer with the charges of $\mathrm{Zn}^{2+}$ and $\mathrm{OH}^{-}$. By this reason, more $\mathrm{Zn}^{2+}$ and $\mathrm{OH}^{-}$ions are diffused on the $\mathrm{ZnO}$ seeds, which results in an increased $\mathrm{ZnO}$ nanorod length with increased $\mathrm{ZnO}$ seed layer annealing temperature [38]. However, further increase annealing temperature of the seed layer may result in shorter $\mathrm{ZnO}$ nanorods length that can be due to structural deterioration.

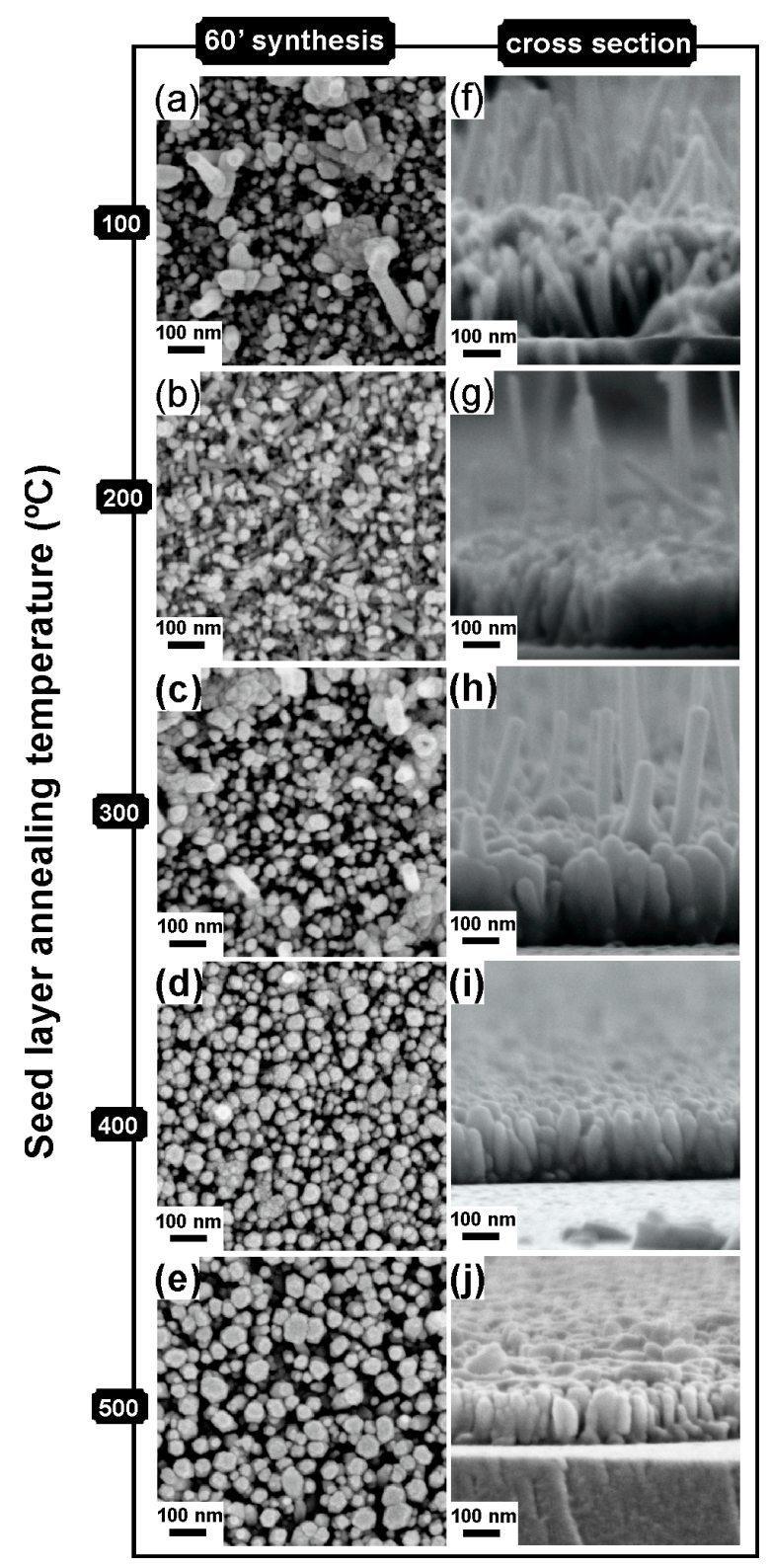

Figure 4. (a-e) SEM images; and ( $\mathbf{f}-\mathbf{j}$ ) cross section images of $\mathrm{ZnO}$ nanorod arrays produced by hydrothermal method and assisted by microwave radiation, with different seed layer annealing temperature $\left(100{ }^{\circ} \mathrm{C}, 200{ }^{\circ} \mathrm{C}, 300{ }^{\circ} \mathrm{C}, 400{ }^{\circ} \mathrm{C}\right.$ and $500{ }^{\circ} \mathrm{C}$, respectively). 
The increase of annealing temperature of $\mathrm{ZnO}$ seed layer will enhance the interaction of the grains, leading the grains to merge together to form rough $\mathrm{ZnO}$ seeds, resulting in larger diameters of the synthesized $\mathrm{ZnO}$ nanorods [39]. Thus, the grain size of $\mathrm{ZnO}$ seed layer is a key factor that will influence the nucleation of $\mathrm{ZnO}$ nanorod arrays.

\subsection{Optical Properties}

Optical band gaps of $\mathrm{ZnO}$ nanorod arrays ware evaluated from transmittance data through the well-known Tauc relation, for direct band semiconductors (Equation (2)) [40]:

$$
(\alpha h v)^{\mathrm{m}}=\mathrm{A}\left(h v-E_{g}\right)
$$

where $\alpha$ is the absorption coefficient; $\mathrm{A}$ is an energy-independent constant; $\mathrm{m}$ is a constant that determines the type of the optical transition $(m=2$ for allowed direct transitions and $m=1 / 2$ for allowed indirect transitions), $E_{g}$ is the optical band gap, $h$ is the Planck constant, and $v$ is the frequency.

The optical band gap was obtained by extrapolating $(\alpha h v)^{2} v s . h v$ and the results are presented in Figure 5. The insets show the optical transmittance of the $\mathrm{ZnO}$ seed layers and the $\mathrm{ZnO}$ nanorod arrays. The $\mathrm{ZnO}$ nanostructured films were found to be transparent in the visible range, with an average transmittance between $75 \%$ and $80 \%$. Such high transmittance of the $\mathrm{ZnO}$ seed layers is a consequence of his low thickness $(\sim 50 \mathrm{~nm})$ and small and highly connected $\mathrm{ZnO}$ grains. After the growth of $\mathrm{ZnO}$ nanorods, where the thickness increases to $180-300 \mathrm{~nm}$, the transmittance remained the same. The high transparency of $\mathrm{ZnO}$ nanorod array is due to their high columnar oriented grains and for being well-aligned perpendicular to the substrate. These results corroborate the SEM surface and cross-section images.
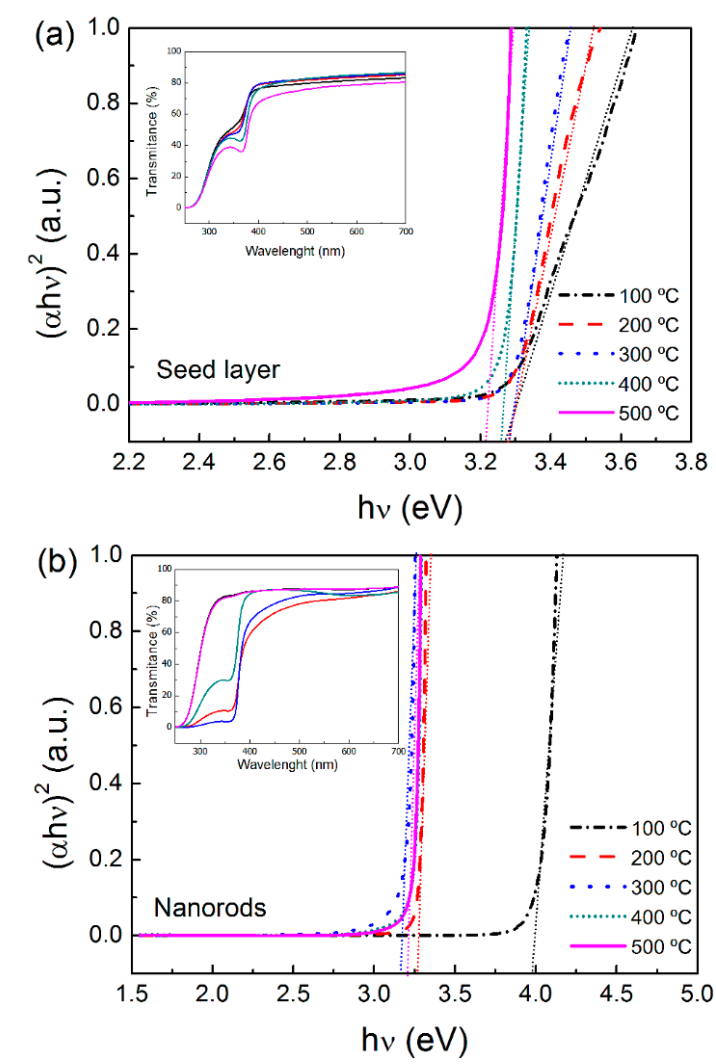

Figure 5. Band gap of: (a) ZnO seed layers at different annealing temperatures; and (b) ZnO nanorod arrays grown above these seed layers. The insets show the optical transmittance of the produced ZnO materials. 
The estimated band gaps of $\mathrm{ZnO}$ seed layers were found to be $3.30 \mathrm{eV}$, for annealing temperatures of 100,200 , and $300{ }^{\circ} \mathrm{C}$, and 3.26 and $3.22 \mathrm{eV}$ for annealing temperatures of 400 and $500{ }^{\circ} \mathrm{C}$, respectively. The $\mathrm{ZnO}$ seed layer band gap decreased for higher annealing temperatures, which is in accordance with previous reports that showed that this effect of the annealing temperature on the optical band gap is associated with the increase of crystallites size [41].

In the case of $\mathrm{ZnO}$ nanorod arrays, band gap values were 3.98, 3.27, 3.17, 3.20 and $3.20 \mathrm{eV}$ for $100,200,300,400$, and $500{ }^{\circ} \mathrm{C}$, respectively. It is observed that the band gap initially decreased (for temperatures from 100 to $300^{\circ} \mathrm{C}$ ) followed by a slightly increase for higher temperatures (for 400 and $\left.500{ }^{\circ} \mathrm{C}\right)$.

There are several parameters that may influence the optical band gap of a semiconductor material, like the residual strain, defects and grain size confinement. It is well known that the band gap usually decreases with the increase of grain size and thickness, which were not observed in these $\mathrm{ZnO}$ nanorod arrays. The increase in the energy band gap with the increase annealing temperature observed for higher temperatures $\left(400\right.$ and $500^{\circ} \mathrm{C}$ ), may be attributed to an expected diminution of oxygen vacancy defects in the $\mathrm{ZnO}$ nanostructures, hence diminishing the density of mid-gap states induced by oxygen vacancies [42].

\subsection{ZnO Nanorods Array UV Sensor}

Ultraviolet (UV) is a high energy beam with photon energies varying from 3.0 to $12.4 \mathrm{eV}$ $(400-10 \mathrm{~nm})$, which overlaps with the band gap of zinc oxide, around $3.4 \mathrm{eV}$ [43]. The use of nanostructures for sensing applications have the advantage of a high surface area and electronic processes are strongly influenced by surface processes [13]. The sensing process is governed by the oxygen vacancies on the surface that influences the electronic properties of $\mathrm{ZnO}$. Upon oxidation, with the adsorption of molecules containing a high concentration of $\mathrm{O}_{2}$ at vacancy sites that accept electrons, electrons are withdrawn and effectively depleted from the conduction band leading to reduction of conductivity. On the other hand, reducing molecules can react with surface adsorbed oxygen leaving behind an electron and a higher conductivity [13]. In consequence, the exposure to UV radiation is an efficient way to excite the hole-electron pairs in the sensing materials, such that the measured resistance of the semiconductor metal oxides is significantly reduced [43].

In the dark, the oxygen molecules adsorb on the $\mathrm{ZnO}$ nanorod surface and capture the free electrons present in the n-type oxide semiconductor (Equation (3)) and a low conductive depletion layer is formed near the surface, which results in the reduction of the conduction layer. When the $\mathrm{ZnO}$ nanorods are irradiated with $\mathrm{UV}$ radiation, with photon energy above $\mathrm{ZnO}$ band-gap energy $(E g)$, the electron-hole pairs are photogenerated (Equation (4)) and the holes migrate to the surface along the potential slope. This potential slope is produced by band bending and the discharge of the negatively charged adsorbed oxygen ions through surface electro-hole recombination (Equation (5)). Consequently, oxygen is photodesorbed from surface [44].

$$
\begin{gathered}
\mathrm{O}_{2}(g)+e^{-} \rightarrow \mathrm{O}_{2}^{-}(a d) \\
h v \rightarrow e^{-}+h^{+} \\
h^{+}+\mathrm{O}_{2}^{-}(a d) \rightarrow \mathrm{O}_{2}(g)
\end{gathered}
$$

A schematic of these reactions can be observed in Figure 6 . 

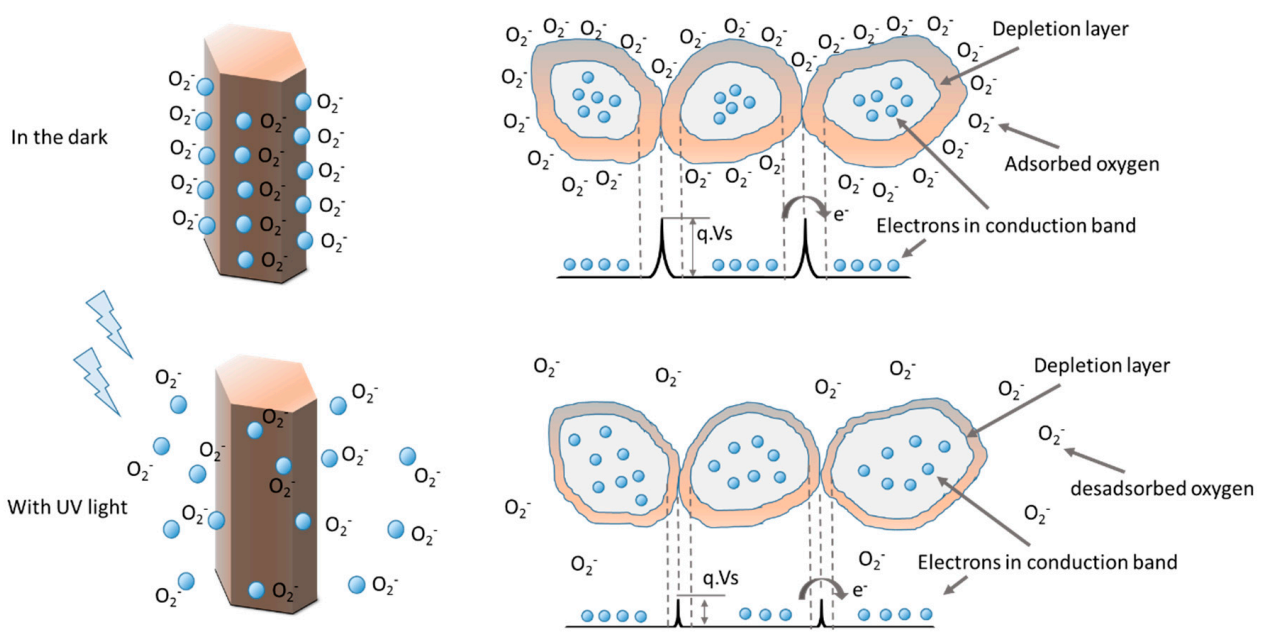

Figure 6. Schematic of the relation between the band model and barrier at intergranular $\mathrm{ZnO}$ nanoparticles with the UV off and the UV on [45].

The sensitivity of nanostructured $\mathrm{ZnO}$ as a sensor element is comparatively high due to the grain-size effect [46]. It is well known that the sensing mechanism of $\mathrm{ZnO}$ belongs to the surface-controlled type. The sensitivity variation is related to the grain size, geometry, surface state, oxygen adsorption quantity, active energy of oxygen adsorption and lattice defects [46]. Usually, the smaller the grain size, specific surface area and oxygen adsorption quantity, the higher is the sensitivity of a sensor. However, for nano-grain based sensors, the sensing properties are influenced not only by the microstructural features, such as the grain size, the geometry, but also by the connectivity between the grains and grains defects.

To characterize the $\mathrm{ZnO}$ nanorod arrays as a UV sensor, interdigital contacts were screen printed on top of the $\mathrm{ZnO}$ seed layer with the grown nanorod arrays (see scheme in Figure 7). The $\mathrm{ZnO}$ nanorod arrays were then subjected to irradiation cycles of ultraviolet radiation.
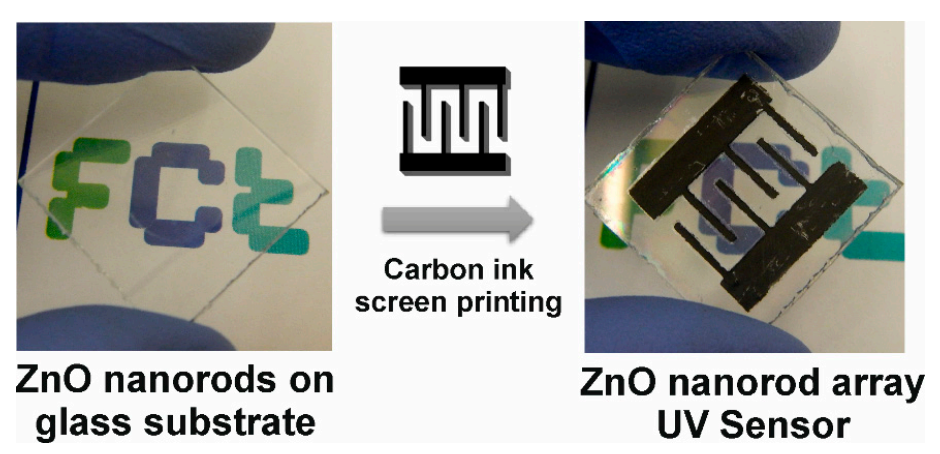

Figure 7. Photograph of the $\mathrm{ZnO}$ nanorod array UV sensor with contacts produced by screen printed of carbon ink.

Figure 8 shows the time resolved photocurrent of $\mathrm{ZnO}$ nanorods UV sensor, produced with different annealing temperatures, in response to turning on/off the UV radiation, at room temperature. It can be seen that the $\mathrm{ZnO}$ nanorods array sensor produced with an annealing temperature of $500{ }^{\circ} \mathrm{C}$ displayed enhanced sensing performance. Under the bias voltage of $5 \mathrm{~V}$, the photocurrent exponential increased from $0.5 \mu \mathrm{A}$ to $0.1 \mathrm{~mA}$ for the material with an annealing temperature of $100^{\circ} \mathrm{C}$ and up to $5.5 \mathrm{~mA}$ for the one produced with an annealing temperature of $500{ }^{\circ} \mathrm{C}$, within about $60 \mathrm{~s}$, with saturation in the on-state. After the UV radiation was turned off, the current decreased again to the initial value of current. 


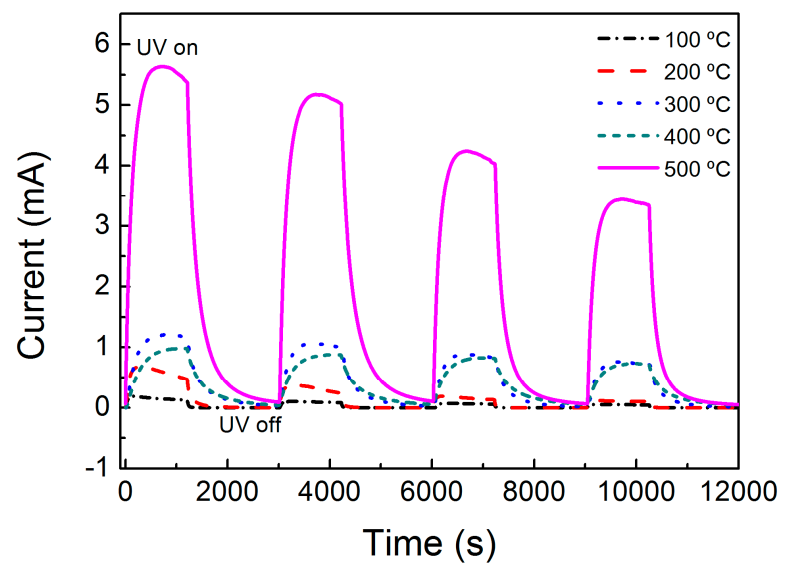

Figure 8. Cycling behaviour of $\mathrm{ZnO}$ nanorods based UV sensors.

The values of dark currents and photocurrents of the produced materials were measured and are presented in Table 2.

Table 2. Dark currents and photocurrents of the produced materials.

\begin{tabular}{cccccc}
\hline Annealing Temperature & $\mathbf{1 0 0}{ }^{\circ} \mathbf{C}$ & $\mathbf{2 0 0}{ }^{\circ} \mathbf{C}$ & $\mathbf{3 0 0}{ }^{\circ} \mathbf{C}$ & $\mathbf{4 0 0}{ }^{\circ} \mathbf{C}$ & $500{ }^{\circ} \mathbf{C}$ \\
\hline Dark current (A) & $5.0 \times 10^{-7}$ & $1.0 \times 10^{-6}$ & $3.0 \times 10^{-5}$ & $4.0 \times 10^{-5}$ & $9.0 \times 10^{-5}$ \\
Photocurrent (A) & $1.0 \times 10^{-4}$ & $3.7 \times 10^{-4}$ & $8.7 \times 10^{-4}$ & $1.0 \times 10^{-3}$ & $5.0 \times 10^{-3}$ \\
\hline
\end{tabular}

The responsivity, $R$, of the fabricated UV sensors can be calculated according to Equation (6) [47]:

$$
R=\frac{I_{p h}-I_{d a r k}}{P_{U V}}
$$

where $I_{p h}$ is the UV sensor photocurrent; $I_{\text {dark }}$ is the UV sensor dark current; and $P_{U V}$ is the power of the UV source. For the $\mathrm{ZnO}$ nanorod arrays UV sensor, produced with different seed layer annealing temperatures, the calculated responsivity was $0.008 \mathrm{~mA} / \mathrm{W}, 0.03 \mathrm{~mA} / \mathrm{W}, 0.07 \mathrm{~mA} / \mathrm{W}, 0.08 \mathrm{~mA} / \mathrm{W}$ and $0.4 \mathrm{~mA} / \mathrm{W}$, for annealing temperatures of $100{ }^{\circ} \mathrm{C}, 200^{\circ} \mathrm{C}, 300^{\circ} \mathrm{C}, 400^{\circ} \mathrm{C}$ and $500{ }^{\circ} \mathrm{C}$, respectively.

Thus, the $\mathrm{ZnO}$ nanorod array UV sensor, produced with a seed layer subjected to an annealing temperature of $500{ }^{\circ} \mathrm{C}$, presents a photo response 50 times superior when compared with sample produced with a seed layer annealing temperature of $100^{\circ} \mathrm{C}$.

The higher sensitivity for the material annealed at $500{ }^{\circ} \mathrm{C}$ can be related to the reduction of the surface-defect-related trap centers that results from the increase of the seed layer annealing temperature, hence modifying the quality of the $\mathrm{ZnO}$ nanorods grown by hydrothermal method and assisted by microwave radiation, resulting in a improvement of their UV response [48]. The $\mathrm{ZnO}$ nanorods produced using seed layers with a higher annealing temperature will present higher cystalline content (proved by the XRD results) and less structural defects.

The produced $\mathrm{ZnO}$ nanorod array UV sensors presents low values of decay time after the UV radiation is turned off, and this decay is related with the evacuation of the charge carries. It is expected that the films annealed at higher temperatures presents a lower decay value due to the annihilation of surface trap [49].

Several factors may be responsible for the high values obtained for decay time, such as the annealing temperature, the thickness of nanorods and even the type and design of electrical contacts that are used. For this sort of sensors, as the main goal is to use low cost techniques, the contacts used were based of carbon ink and deposited by screen printing technique. In such approach, only part of the nanorods (the top) is kept in contact with the ink (that is not so conductive as an aluminum 
or silver contact). This can lead to the photogenerated carriers to be kept trapped within the $\mathrm{ZnO}$ nanorods for longer period of time before being injected into the carbon contacts, and thus leading to a slow saturation in photocurrent and slow decay when the UV radiation is turned off [50]. This may be the probable cause of having sensors with a long decay response. The layout of the contacts can be improved in order to reduce the UV sensor decay time.

\section{Experimental Details}

\subsection{Synthesis of $\mathrm{ZnO}$ Nanostructures}

The $\mathrm{ZnO}$ thin films to serve as a seed were deposited on glass substrate by spin-coating method. A coating solution was prepared from zinc acetate dihydrate $\left(\mathrm{Zn}\left(\mathrm{CH}_{3} \mathrm{COO}\right)_{2} \cdot 2 \mathrm{H}_{2} \mathrm{O} ; 98 \%\right.$, CAS: 5970-45-6), ethanolamine, MEA $\left(\mathrm{C}_{2} \mathrm{H}_{7} \mathrm{NO} ; 99 \%\right.$, CAS: 141-43-5) and 2-methoxiethanol $\left(\mathrm{C}_{3} \mathrm{H}_{8} \mathrm{O}_{2}, 99.8 \%\right.$, CAS: 109-86-4), all from Sigma-Aldrich (St. Louis, MO, USA). The reagents were used without further purification. In a typical experiment, zinc acetate solution was prepared by dissolving $\mathrm{Zn}\left(\mathrm{CH}_{3} \mathrm{COO}\right)_{2} \cdot 2 \mathrm{H}_{2} \mathrm{O}$ in 2-methoxiethanol and adding the ethanolamine. The concentration of the solution was chosen to be $0.35 \mathrm{M}$, in a proportion of 1:1 of zinc acetate and ethanolamine. The resulting solution was then stirred for $1 \mathrm{~h}$ at $60^{\circ} \mathrm{C}$ and filtered afterward to yield a clear and homogeneous solution and then used for preparing films by spin-coating method. Before deposition, $20 \times 20 \mathrm{~mm}^{2}$ glass substrates were successively cleaned with acetone, ethanol, and deionized water in an ultrasonic bath. The prepared solution was then spin coated on the substrate at $3000 \mathrm{rpm}$ for $35 \mathrm{~s}$ at room temperature. After deposition, the films were dried for $10 \mathrm{~min}$ in a hot plate at $300{ }^{\circ} \mathrm{C}$ in order to remove the used solvent. After repeating the coating-drying cycles 4 times the substrates were annealed for $1 \mathrm{~h}$. The annealing temperature was varied from 100 to $500^{\circ} \mathrm{C}$ in order to investigate its effect in the resulting $\mathrm{ZnO}$ nanorod arrays.

After uniformly coating the glass substrates with $\mathrm{ZnO}$ thin films, $\mathrm{ZnO}$ nanorod arrays were synthesized by hydrothermal method assisted by microwave radiation. The $\mathrm{ZnO}$ seeded substrates $\left(20 \times 20 \mathrm{~mm}^{2}\right)$ were placed at an angle against the vessel, with the seed layer facing down [51] (see Figure 9) and filled with an aqueous solution of $25 \mathrm{mM}$ zinc nitrate hexahydrate $\left(\mathrm{Zn}\left(\mathrm{NO}_{3}\right)_{2} \cdot 6 \mathrm{H}_{2} \mathrm{O}\right.$; $98 \%$, CAS: 10196-18-6) and $25 \mathrm{mM}$ hexamethylenetetramine $\left(\mathrm{C}_{6} \mathrm{H}_{12} \mathrm{~N}_{4}\right)_{2} ; 99 \%$, CAS: 100-97-0), both from Sigma Aldrich (St. Louis, MO, USA).

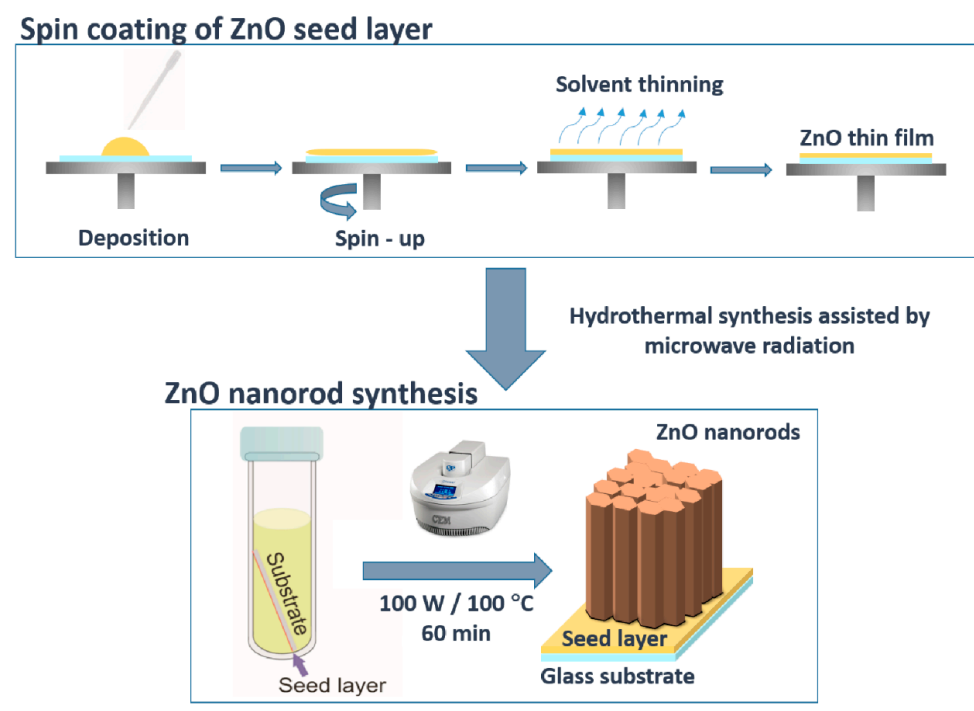

Figure 9. Scheme of the $\mathrm{ZnO}$ seed layer deposition using the spin coating method, followed by $\mathrm{ZnO}$ nanorod arrays synthesized by hydrothermal method assisted by microwave radiation. 
The $\mathrm{ZnO}$ nanorod synthesis was carried out with a microwave power input of $100 \mathrm{~W}$ and a constant temperature of $100^{\circ} \mathrm{C}$, for $60 \mathrm{~min}$. After each synthesis process, the materials were cleaned with deionized water and dried with compressed air. Figure 9 represents a schematic of the production process of $\mathrm{ZnO}$ seed layer and the subsequent synthesis of $\mathrm{ZnO}$ nanorod arrays.

\subsection{Characterization Techniques}

Differential scanning calorimetric measurements (DSC) of spin coating solution were carried out with a Simultaneous Thermal Analyser (TGA-DSC-STA 449 F3 Jupiter, Netzsch-Geratebau GmbH, Selb, Germany). Approximately $20 \mathrm{mg}$ of each sample was loaded into an open aluminum crucible and heated from room temperature to $550{ }^{\circ} \mathrm{C}$ with a heating rate of $5^{\circ} \mathrm{C} \cdot \mathrm{min}^{-1}$, in air.

The crystallinity of the as-prepared materials was determined using a PANalytical's X'Pert PRO MRD X-ray diffractometer (PANalytical B.V., Almelo, The Netherlands), with a monochromatic CuK $\alpha$ radiation source (wavelength $1.540598 \AA$ ). XRD measurements were carried out from $30^{\circ}$ to $40^{\circ}$ $(2 \theta)$, with a scanning step size of $0.016^{\circ}$. The morphology of $\mathrm{ZnO}$ seed layer and nanorods were characterized by SEM-FIB using a Carl Zeiss AURIGA CrossBeam workstation instrument (Carl Zeiss Microscopy GmbH, Oberkochen, Germany) equipped with an Oxford X-ray Energy Dispersive Spectrometer (Carl Zeiss Microscopy GmbH, Oberkochen, Germany).

Atomic force microscopy (AFM) was used to measure the roughness of the seed layers, using an MFP-3D stand alone Asylum Research instrument (Asylum Research Oxford Instruments, Goleta, CA, USA) operated in tapping mode using Olympus AC160TS silicon probes (Olympus Corporation, Tokyo, Japan) attached to cantilevers with a nominal quality factor of 550, spring constant of $26.1 \mathrm{~N} / \mathrm{m}$ and frequency resonance peak at $300 \mathrm{kHz}$. The scanning range was $1 \times 1 \mu \mathrm{m}^{2}$ with a resolution of $256 \times 256$ lines.

The transmittance spectra was obtained in the $250-800 \mathrm{~nm}$ range using a Perkin Elmer lambda 950 UV/VIS/NIR spectrophotometer (Perkin Elmer, Inc., Waltham, MA, USA). The band gap of ZnO was estimated from obtained transmittance spectra using the Tauc plot method [52,53].

\subsection{Characterization of ZnO Nanorod Arrays as a UV Sensor}

The synthesized $\mathrm{ZnO}$ nanorod arrays were characterized as a UV sensor, using a potentiostat model 600, from Gamry Instruments, Inc. (Warminster, PA, USA), in a chronoamperiometry configuration, with a constant applied voltage of $5 \mathrm{~V}$. For interdigital electrical contacts, a carbon resistive ink, PE-C-774, from Conductive Compounds (Hudson, NH, USA), was used. The ZnO nanorod arrays were subjected to UV irradiation with an ultraviolet lamp, model TK-2028 (Hongguang Optics International Industry Co. Ltd., Ningbo, China) with an intensity of $6 \mathrm{~W}$ at a wavelength of $254 \mathrm{~nm}$. The produced sensor was irradiated for $20 \mathrm{~min}$ followed by $20 \mathrm{~min}$ in off state.

\section{Conclusions}

The present work investigated the effect of the annealing temperature of the seed layer on the growth of $\mathrm{ZnO}$ nanorod arrays produced under hydrothermal synthesis assisted by microwave radiation and its direct influence on the final UV sensor performance. It has been demonstrated the successfully growth of $\mathrm{ZnO}$ nanorods, forming oriented nanorod arrays aligned along the (002) plane. The $\mathrm{ZnO}$ seed layer and nanorod arrays were observed by AFM and SEM revealing growth homogeneity and roughness with the increase of seed layer annealing temperature. All the $\mathrm{ZnO}$ nanorod arrays were tested as UV sensors, showing an increase in the sensitivity with the increase of seed layer annealing temperature. The UV sensor response of $\mathrm{ZnO}$ nanorods produced with a seed layer annealed at $500{ }^{\circ} \mathrm{C}$ was 50 times superior to those produced with a seed layer annealed at $100{ }^{\circ} \mathrm{C}$. This work demonstrated that the $\mathrm{ZnO}$ seed layer annealing temperature, produced with a low cost method, have strong influence on the $\mathrm{ZnO}$ nanorods growth and on their sensing properties, by affecting the $\mathrm{ZnO}$ grains microstructure and their crystalographic defects. Moreover, it can be concluded that by using microwave assisted synthesis to grow $\mathrm{ZnO}$ nanorod arrays on seeded films 
annealed in a wide range of temperatures, it is possible to grow $\mathrm{ZnO}$ nanorods arrays and produce UV sensors in all type of substrates, from silicon and glass (that support high temperatures) to polymeric or paper substrates (that only support low temperatures).

Acknowledgments: This work was partially financed by FEDER funds through the COMPETE 2020 Programme and National Funds through FCT (Portuguese Foundation for Science and Technology) through BPD/76992/2011 and under the projects UID/CTM/50025/2013 and EXCL/CTM-NAN/0201/2012. Sofia Henriques Ferreira acknowledges the support from the Portuguese Foundation for Science and Technology through the AdvaMTech PhD program scholarship PD/BD/114086/2015.

Author Contributions: Ana Pimentel and Sofia Henriques Ferreira performed the experiments; optical and sensor characterization was performed by Sofia Henriques Ferreira; the DSC-TG and XRD characterization was performed by Ana Pimentel; Daniela Nunes and Tomas Calmeiro performed the SEM and AFM characterization; and the work and paper was under the supervision of Rodrigo Martins and Elvira Fortunato.

Conflicts of Interest: The authors declare no conflict of interest.

\section{References}

1. Coleman, V.A.; Jagadish, C. Basic Properties and Applications of ZnO. In Zinc Oxide Bulk, Thin Films and Nanostructures; Jagadish, C., Pearton, S., Eds.; Elsevier Science Ltd.: Oxford, UK, 2006; Chapter 1; pp. 1-20.

2. Barquinha, P.; Fortunato, E.; Gonçalves, A.; Pimentel, A.; Marques, A.; Pereira, L.; Martins, R. A Study on the Electrical Properties of ZnO Based Transparent TFTs. Mater. Sci. Forum 2006, 514-516, 68-72. [CrossRef]

3. Fortunato, E.; Gonçalves, A.; Marques, A.; Pimentel, A.; Barquinha, P.; Águas, H.; Pereira, L.; Raniero, L.; Gonçalves, G.; Ferreira, I.; et al. Multifunctional Thin Film Zinc Oxide Semiconductors: Application to Electronic Devices. Mater. Sci. Forum 2006, 514-516, 3-7. [CrossRef]

4. Djurišić, A.B.; Ng, A.M.C.; Chen, X.Y. ZnO nanostructures for optoelectronics: Material properties and device applications. Prog. Quantum Electron. 2010, 34, 191-259. [CrossRef]

5. Pimentel, A.; Gonçalves, A.; Marques, A.; Martins, R.; Fortunato, E. Role of the thickness on the electrical and optical performances of undoped polycrystalline zinc oxide films used as UV detectors. J. Non Cryst. Solids 2006, 352, 1448-1452. [CrossRef]

6. Pimentel, A.C.; Gonçalves, A.; Marques, A.; Martins, R.; Fortunato, E. Zinc Oxide Thin Films used as an Ozone Sensor at Room Temperature. MRS Proc. 2006, 915. [CrossRef]

7. Bai, S.; Wu, W.; Qin, Y.; Cui, N.; Bayerl, D.J.; Wang, X. High-Performance Integrated ZnO Nanowire UV Sensors on Rigid and Flexible Substrates. Adv. Funct. Mater. 2011, 21, 4464-4469. [CrossRef]

8. Arya, S.K.; Saha, S.; Ramirez-Vick, J.E.; Gupta, V.; Bhansali, S.; Singh, S.P. Recent advances in ZnO nanostructures and thin films for biosensor applications: Review. Anal. Chim. Acta 2012, 737, 1-21. [CrossRef] [PubMed]

9. Zhang, Y.; Kang, Z.; Yan, X.; Liao, Q. ZnO nanostructures in enzyme biosensors. Sci. China Mater. 2015, 58, 60-76. [CrossRef]

10. Kumar, B.; Kim, S.-W. Energy harvesting based on semiconducting piezoelectric ZnO nanostructures. Nano Energy 2012, 1, 342-355. [CrossRef]

11. Wang, Z.L.; Song, J. Piezoelectric nanogenerators based on zinc oxide nanowire arrays. Science 2006, 312, 242-246. [CrossRef] [PubMed]

12. Wang, Z.L. Zinc oxide nanostructures: Growth, properties and applications. J. Phys. Condens. Matter 2004, 16, R829-R858. [CrossRef]

13. Schmidt-Mende, L.; MacManus-Driscoll, J.L. ZnO—Nanostructures, defects, and devices. Mater. Today 2007, 10, 40-48. [CrossRef]

14. Baruah, S.; Dutta, J. Hydrothermal growth of ZnO nanostructures. Sci. Technol. Adv. Mater. $2009,10$. [CrossRef]

15. Bai, S.; Chen, L.; Li, D.; Yang, W.; Yang, P.; Liu, Z.; Chen, A.; Liu, C.C. Different morphologies of ZnO nanorods and their sensing property. Sens. Actuators B Chem. 2010, 146, 129-137.

16. Spencer, M.J.S. Gas sensing applications of 1D-nanostructured zinc oxide: Insights from density functional theory calculations. Prog. Mater. Sci. 2012, 57, 437-486. [CrossRef]

17. Wang, L.; Kang, Y.; Liu, X.; Zhang, S.; Huang, W.; Wang, S. ZnO nanorod gas sensor for ethanol detection. Sens. Actuators B Chem. 2012, 162, 237-243. [CrossRef] 
18. Lupan, O.; Emelchenko, G.A.; Ursaki, V.V.; Chai, G.; Redkin, A.N.; Gruzintsev, A.N.; Tiginyanu, I.M.; Chow, L.; Ono, L.K.; Roldan Cuenya, B.; et al. Synthesis and characterization of ZnO nanowires for nanosensor applications. Mater. Res. Bull. 2010, 45, 1026-1032. [CrossRef]

19. Pimentel, A.; Nunes, D.; Duarte, P.; Rodrigues, J.; Costa, F.M.; Monteiro, T.; Martins, R.; Fortunato, E. Synthesis of Long ZnO Nanorods under Microwave Irradiation or Conventional Heating. J. Phys. Chem. C 2014, 118, 14629-14639. [CrossRef]

20. Wu, L.; Song, F.; Fang, X.; Guo, Z.-X.; Liang, S. A practical vacuum sensor based on a ZnO nanowire array. Nanotechnology 2010, 21. [CrossRef] [PubMed]

21. Ajimsha, R.S.; Manoj, R.; Aneesh, P.M.; Jayaraj, M.K. Violet luminescence from ZnO nanorods grown by room temperature pulsed laser deposition. Curr. Appl. Phys. 2010, 10, 693-697. [CrossRef]

22. Shinde, S.D.; Patil, G.E.; Kajale, D.D.; Gaikwad, V.B.; Jain, G.H. Synthesis of ZnO nanorods by spray pyrolysis for $\mathrm{H}_{2} \mathrm{~S}$ gas sensor. J. Alloys Compd. 2012, 528, 109-114. [CrossRef]

23. Gurav, K.V.; Gang, M.G.; Shin, S.W.; Patil, U.M.; Deshmukh, P.R.; Agawane, G.L.; Suryawanshi, M.P.; Pawar, S.M.; Patil, P.S.; Lokhande, C.D.; et al. Gas sensing properties of hydrothermally grown ZnO nanorods with different aspect ratios. Sens. Actuators B Chem. 2014, 190, 439-445. [CrossRef]

24. Pimentel, A.; Rodrigues, J.; Duarte, P.; Nunes, D.; Costa, F.M.; Monteiro, T.; Martins, R.; Fortunato, E. Effect of solvents on $\mathrm{ZnO}$ nanostructures synthesized by solvothermal method assisted by microwave radiation: A photocatalytic study. J. Mater. Sci. 2015, 50, 5777-5787. [CrossRef]

25. Hassan, J.J.; Mahdi, M.A.; Chin, C.W.; Abu-Hassan, H.; Hassan, Z. Room temperature hydrogen gas sensor based on $\mathrm{ZnO}$ nanorod arrays grown on $\mathrm{SiO}_{2} / \mathrm{Si}$ substrate via a microwave-assisted chemical solution method. J. Alloys Compd. 2013, 546, 107-111. [CrossRef]

26. Rai, P.; Song, H.-M.; Kim, Y.-S.; Song, M.-K.; Oh, P.-R.; Yoon, J.-M.; Yu, Y.-T. Microwave assisted hydrothermal synthesis of single crystalline $\mathrm{ZnO}$ nanorods for gas sensor application. Mater. Lett. 2012, 68, 90-93. [CrossRef]

27. Huang, J.-S.; Lin, C.-F. Influences of $\mathrm{ZnO}$ sol-gel thin film characteristics on $\mathrm{ZnO}$ nanowire arrays prepared at low temperature using all solution-based processing. J. Appl. Phys. 2008, 103. [CrossRef]

28. Hayes, B.L. Microwave Synthesis: Chemistry at the Speed of Light; CEM Publishing: Matthews, NC, USA, 2002.

29. Nunes, D.; Santos, L.; Duarte, P.; Pimentel, A.; Pinto, J.V.; Barquinha, P.; Carvalho, P.A.; Fortunato, E.; Martins, R. Room temperature synthesis of $\mathrm{Cu}_{2} \mathrm{O}$ nanospheres: Optical properties and thermal behavior. Microsc. Microanal. 2015, 21, 108-119. [CrossRef] [PubMed]

30. Gonçalves, A.; Resende, J.; Marques, A.C.; Pinto, J.V.; Nunes, D.; Marie, A.; Goncalves, R.; Pereira, L.; Martins, R.; Fortunato, E. Smart optically active $\mathrm{VO}_{2}$ nanostructured layers applied in roof-type ceramic tiles for energy efficiency. Sol. Energy Mater. Sol. Cells 2016, 150, 1-9. [CrossRef]

31. Ohyama, M.; Kouzuka, H.; Yoko, T. Sol-gel preparation of $\mathrm{ZnO}$ films with extremely preferred orientation along (002) plane from zinc acetate solution. Thin Solid Films 1997, 306, 78-85. [CrossRef]

32. Ohyama, M.; Kozuka, H.; Yoko, T.; Sakka, S. Preparation of ZnO films with preferential orientation by sol-gel method. J. Ceram. Soc. Jpn. 1996, 104, 296-300. [CrossRef]

33. Znaidi, L. Sol-gel-deposited ZnO thin films: A review. Mater. Sci. Eng. B 2010, 174, 18-30. [CrossRef]

34. Lin, C.-C.; Li, Y.-Y. Synthesis of ZnO nanowires by thermal decomposition of zinc acetate dihydrate. Mater. Chem. Phys. 2009, 113, 334-337. [CrossRef]

35. Khomyak, V.V.; Slyotov, M.M.; Shtepliuk, I.I.; Lashkarev, G.V.; Slyotov, O.M.; Marianchuk, P.D.; Kosolovskiy, V.V. Annealing effect on the near-band edge emission of ZnO. J. Phys. Chem. Solids 2013, 74, 291-297. [CrossRef]

36. Cullity, B.D. Elements of X ray Diffraction; Addison-Wesley Publisher Company, Inc.: Boston, MA, USA, 1956.

37. Hoon, J.-W.; Chan, K.-Y.; Krishnasamy, J.; Tou, T.-Y.; Knipp, D. Direct current magnetron sputter-deposited ZnO thin films. Appl. Surf. Sci. 2011, 257, 2508-2515. [CrossRef]

38. Ridhuan, N.S.; Razak, K.A.; Lockman, Z.; Abdul Aziz, A. Structural and morphology of ZnO nanorods synthesized using $\mathrm{ZnO}$ seeded growth hydrothermal method and its properties as UV sensing. PLoS ONE 2012, 7. [CrossRef] [PubMed]

39. Baruah, S.; Dutta, J. Effect of seeded substrates on hydrothermally grown ZnO nanorods. J. Sol Gel Sci. Technol. 2009, 50, 456-464. [CrossRef] 
40. Talebian, N.; Amininezhad, S.M.; Doudi, M. Controllable synthesis of ZnO nanoparticles and their morphology-dependent antibacterial and optical properties. J. Photochem. Photobiol. B 2013, 120, 66-73. [CrossRef] [PubMed]

41. Hong, R.; Huang, J.; He, H.; Fan, Z.; Shao, J. Influence of different post-treatments on the structure and optical properties of zinc oxide thin films. Appl. Surf. Sci. 2005, 242, 346-352. [CrossRef]

42. Panda, S.K.; Jacob, C. Preparation of transparent $\mathrm{ZnO}$ thin films and their application in UV sensor devices. Solid State Electron. 2012, 73, 44-50. [CrossRef]

43. Chou, C.-S.; Wu, Y.-C.; Lin, C.-H. Oxygen sensor utilizing ultraviolet irradiation assisted ZnO nanorods under low operation temperature. RSC Adv. 2014, 4, 52903-52910. [CrossRef]

44. Zhai, T.; Fang, X.; Liao, M.; Xu, X.; Zeng, H.; Yoshio, B.; Golberg, D. A Comprehensive Review of One-Dimensional Metal-Oxide Nanostructure Photodetectors. Sensors 2009, 9, 6504-6529. [CrossRef] [PubMed]

45. Madou, M.J.; Morrison, S.R. Chemical Sensing with Solid State Devices; Academic Press, Inc.: New York, NY, USA, 1989.

46. Fryxell, G.E.; Cao, G. Environmental Applications of Nanomaterials: Synthesis, Sorbents and Sensors; Imperial College Press: London, UK, 2007.

47. Mamat, M.H.; Khusaimi, Z.; Zahidi, M.; Mahmood, M.R. Nanorods; Yaln, O., Ed.; InTech: Vienna, Austria, 2012.

48. Zhou, Q.; Chen, W.; Xu, L.; Peng, S. Hydrothermal synthesis of various hierarchical ZnO nanostructures and their methane sensing properties. Sensors 2013, 13, 6171-6182. [CrossRef] [PubMed]

49. Mamat, M.H.; Khalin, M.I.C.; Mohammad, N.N.H.N.; Khusaimi, Z.; Sin, N.D.M.; Shariffudin, S.S.; Zahidi, M.M.; Mahmood, M.R. Effects of Annealing Environments on the Solution-Grown, Aligned Aluminium-Doped Zinc Oxide Nanorod-Array-Based Ultraviolet Photoconductive Sensor. J. Nanomater. 2012, 2012. [CrossRef]

50. Chang, H.; Sun, Z.; Ho, K.Y.-F.; Tao, X.; Yan, F.; Kwok, W.-M.; Zheng, Z. A highly sensitive ultraviolet sensor based on a facile in situ solution-grown $\mathrm{ZnO}$ nanorod/graphene heterostructure. Nanoscale 2011, 3, $258-264$. [CrossRef] [PubMed]

51. Nunes, D.; Pimentel, A.; Pinto, J.V.; Calmeiro, T.R.; Nandy, S.; Barquinha, P.; Pereira, L.; Carvalho, P.A.; Fortunato, E.; Martins, R. Photocatalytic behavior of $\mathrm{TiO}_{2}$ films synthesized by microwave irradiation. Catal. Today 2015. [CrossRef]

52. Pankove, J.I. Optical Processes in Semiconductors; Dover Publications, Inc.: Mineola, NY, USA, 1971.

53. Tauc, J. Optical properties and electronic structure of amorphous Ge and Si. Mater. Res. Bull. 1968, 3, 37-46. [CrossRef]

(C) 2016 by the authors; licensee MDPI, Basel, Switzerland. This article is an open access article distributed under the terms and conditions of the Creative Commons Attribution (CC-BY) license (http://creativecommons.org/licenses/by/4.0/). 